\title{
Short communication: Effect of heat stress on markers of autophagy in the mammary gland during the dry period
}

\author{
S. E. Wohlgemuth, ${ }^{\star 1}$ Y. Ramirez-Lee, ${ }^{*}$ S. Tao,† A. P. A. Monteiro,† B. M. Ahmed, ${ }^{*}$ and G. E. Dahl* \\ *Department of Animal Sciences, University of Florida, Gainesville 32611 \\ †Department of Animal and Dairy Science, University of Georgia, 2360 Rainwater Road, Tifton 31793-5766
}

\begin{abstract}
Heat stress (HT) during the dry period compromises mammary gland (MG) growth, thus negatively affecting subsequent milk yield. Cooling during the late dry period, when mammary tissue proliferates, is a common management practice. However, it neglects MG involution during the early dry period, a process that is accomplished by both apoptosis and autophagy. Our objective was to evaluate the effect of HT on MG autophagy during the early dry period. Holstein cows were dried off $\sim 45 \mathrm{~d}$ before expected calving and randomly assigned to 1 of 2 treatments: HT or cooling (CL). All cows were housed in the same free stall barn during the dry period, but only the stall area for CL cows was equipped with soakers and fans. Rectal temperature and respiration rate were measured daily during the dry period. Mammary gland biopsies were collected from each cow $3 \mathrm{~d}$ before dry-off and on d $3,7,14$, and $22 \pm 2$ after dry-off. Autophagy in the MG was determined by measuring protein expression of 2 autophagic markers, autophagy-related protein 7 and microtubule-associated protein light chain 3 (LC3). The average temperature-humidity index during the dry period was 77.7 , which indicated that HT and CL cows were exposed to significant heat stress. However, the cooling system effectively alleviated heat strain in CL cows by decreasing the rectal temperature (39.0 vs. $\left.39.4^{\circ} \mathrm{C}\right)$ and respiration rate $(47.3$ vs. 71.2 breaths per minute) relative to HT cows. Protein expression of autophagy-related protein 7, a marker for early autophagosome formation, did not change within or between groups. In contrast, protein expression of LC3-II, a marker of autophagosomes, and its precursor LC3-I showed a dynamic expression pattern in MG from CL cows during the early dry period. Relative to HT cows, MG from CL cows displayed higher expression of LC3-I and LC3-II on $\mathrm{d} 7$ and lower expression of LC3-II on d
\end{abstract}

Received November 16, 2015.

Accepted February 16, 2016.

${ }^{1}$ Corresponding author: steffiw@ufl.edu
14 and 22 after dry-off. Collectively, our data provide a possible mechanistic explanation for the impairment of MG capacity in HT dairy cows. Heat stress-related perturbations of autophagic activity may compromise the regenerative MG involution that is necessary for optimal cell proliferation.

Key words: autophagy, dry period, heat stress, mammary gland

\section{Short Communication}

With temperatures rising approximately $0.2^{\circ} \mathrm{C}$ per decade since 1980 (IPCC, 2013: Summary for Policymakers), more and more animals are at risk of being exposed to high ambient temperatures outside their thermal comfort zone for longer periods of time, especially in the southeastern United States. For dairy cows, one of the well-recognized negative effects of increased environmental temperatures and humidity is the decrease in milk production (West, 2003; Collier et al., 2006; Tao et al., 2011). One possible explanation for the detrimental effect of heat stress on lactation performance is the impaired renewal of mammary cells between lactations. We (do Amaral et al., 2009, 2011; Tao et al., 2011) and others (Wolfenson et al., 1988) have reported that heat stress abatement during the entire dry period increases subsequent milk yield, and that mammary cell proliferation is increased in parallel with cooling during the late dry period (Tao et al., 2011). Thus, it appears that environmental heat stress affects mammary gland (MG) remodeling, but the underlying mechanisms are not known.

During the initial phase of the dry period, the MG involutes and senescent cells are removed, which is followed by mammary cell proliferation during the late dry period in preparation for the next lactation, a process that has been reviewed in several publications (Capuco and Akers, 1999; Zarzynska and Motyl, 2008; Capuco and Ellis, 2013). Mammary involution is accomplished by both programmed cell death, namely apoptosis (Capuco et al., 1997), and autophagy (Zarzynska and Motyl, 2008). In contrast to apoptosis, autophagy, 
which literally means "self-eating," can lead to either cell death or cell survival (Codogno and Meijer, 2005). Autophagy is a major homeorhetic mechanism in which intracellular materials, such as proteins, protein aggregates, or organelles, are isolated into double-membrane vesicles called autophagosomes, which are delivered to lysosomes for degradation (Parzych and Klionsky, 2014). However, the importance of autophagy in the involuting bovine MG is still not clear but may play different and important roles depending on the stage of MG development. During mammary involution in the early dry period, autophagy increases dramatically (Zarzynska et al., 2007; Teplova et al., 2013), which may support removal of senescent cells; rescue of mammary cells, including progenitor cells, from destruction; or both (Zarzynska et al., 2007; Gajewska et al., 2013). On the other hand, during the mammary proliferation phase in the late dry period, mammary autophagy returns to baseline levels (Zarzynska et al., 2007) to facilitate the enhanced cell proliferation. Indeed, enhanced autophagy inhibits cell proliferation (Wang and Levine, 2010), whereas decreased autophagy can stimulate mammary cell proliferation (Qu et al., 2003).

Environmental heat stress can cause autophagic dysregulation. Indeed, in vitro studies using short-term heat shock demonstrated a stimulation of autophagy in a variety of cell types (Nivon et al., 2009; Zhao et al., 2009; Hsu et al., 2013). On the other hand, the disturbed hormonal profile caused by heat stress in late gestation dairy cows could result in blunted MG autophagy. For example, estrogen has a stimulatory effect on autophagy in the mammary epithelial BMEUV1 cells (Sobolewska et al., 2009). A heat stress-induced reduction in estrogen (Collier et al., 1982) could negatively affect MG autophagy during the early dry period. However, it is still unknown how heat stress affects autophagy in both mammary involuting and proliferating stages of MG development during the dry period, and this deserves further investigation.

Therefore, the present study aimed to investigate autophagic activity in bovine MG tissue during the early dry period and the effect of chronic environmental heat stress. We compared autophagic activity in MG biopsies taken before and during the dry period from cows that were either heat stressed (HT) or actively cooled (CL). Our hypothesis was that chronic heat stress perturbs autophagic activity during the dry period, thereby negatively affecting MG remodeling.

The Institutional Animal Care and Use Committee of the University of Florida approved all procedures. The study was conducted during the summer of 2014 at the University of Florida Dairy Unit in Hague, Florida. Multiparous Holstein cows were dried off approximately
$45 \mathrm{~d}$ before the expected calving date and randomly assigned to 1 of 2 treatments, HT or CL. During the dry period, all cows were housed in the same freestall barn, but CL cows were cooled with shade, soakers, and fans, whereas HT cows were provided with shade only. Fans in CL pens were always on, and soakers were activated for $1.5 \mathrm{~min}$ at $5 \mathrm{~min}$ intervals when ambient temperature reached $21.1^{\circ} \mathrm{C}$. Air temperature and relative humidity of each pen in the dry cow barn were recorded every $15 \mathrm{~min}$ by Hobo Pro series Temp probes (Onset Computer Corp., Pocasset, MA). The temperaturehumidity index was calculated as described previously (Tao et al., 2011). Rectal temperature was measured and respiration rate was counted daily (1430 h) during the dry period. Mammary biopsies were collected from alternate rear quarters ( $\mathrm{HT}, \mathrm{n}=8$; $\mathrm{CL}, \mathrm{n}=8$ ) $3 \mathrm{~d}$ before dry-off and 3, 7, 14, and $22 \mathrm{~d}$ after dry-off. The mammary biopsy procedure was previously described in detail (Wall et al., 2005; Tao et al., 2011). The biopsies were quickly rinsed with PBS, fat was trimmed off, and then samples were snap frozen in liquid nitrogen before storage at $-80^{\circ} \mathrm{C}$.

Autophagy in MG tissue was assessed by determining protein expression of 2 autophagic markers, autophagyrelated protein 7 (Atg7) and microtubule-associated protein light chain 3 (MAP-LC3, subsequently referred to as LC3), in tissue homogenates. Over 30 proteins contribute to the highly regulated process of autophagy, during which cytoplasmic constituents are engulfed in membrane-bound autophagosomes, which ultimately fuse with a lysosome containing the degradative enzymes. The autophagy protein LC3 is essential for the expansion of the early autophagosome (Abeliovich et al., 2000) and has commonly been used as a marker for autophagic activity in the context of cellular housekeeping and autophagic cell death (Tanida et al., 2004). The precursor pre-LC3 is processed to its cytosolic form, LC3-I, subsequently activated by the autophagy protein Atg7, and lipidated to its membrane-bound form, LC3-II, which localizes to the developing autophagosome. Briefly, tissue samples were homogenized in PBS at $4^{\circ} \mathrm{C}$ using a Polytron PT 2100 homogenizer (Kinematica, Littau-Lucerne, Switzerland), kept on ice for $1 \mathrm{~h}$, and then centrifuged $\left(3,000 \times g, 10 \mathrm{~min}, 4^{\circ} \mathrm{C}\right)$. The pellet was discarded, and the protein concentration was determined in the supernatant (Bradford Reagent, BioRad, Hercules, CA). The sample was then diluted with equal volume of Laemmli sample buffer (BioRad) and boiled for 5 min. Sodium dodecyl sulfate PAGE, electro-transfer of proteins, and immunoblotting were performed as previously described (Wohlgemuth et al., 2010). Antibodies used for immunoblotting were antiLC3 (anti-rabbit LC3, Thermo Scientific, Waltham, 
MA; cat\# PA1-16930, dilution 1:500), anti-Atg7 (antirabbit Atg7, Cell Signaling, Danvers, MA, cat\# 8558, dilution 1:1000), anti- $\beta$-actin (anti-mouse $\beta$-actin, Sigma, St. Louis, MO, cat\# A2228, dilution 1:32,000; loading control), and appropriate secondary antibodies (anti-rabbit IgG horseradish peroxidase-conjugated, Sigma, cat\# A0545, dilution 1:80,000 for LC3 and Atg7; anti-mouse IgG alkaline phosphatase-conjugated, Sigma, cat\# A1293, dilution 1:60,000). Chemiluminescence of bands of interest was detected with a digital G:Box imager (Syngene, Frederick, MD), and band density was analyzed using the manufacturer's analysis software (Gene Tools).

Data were analyzed as repeated measures using the PROC MIXED procedure of SAS 9.4 (SAS Institute Inc., Cary, NC). The SAS model included fixed effects of treatment, time, and treatment $\times$ time interaction with cow (treatment) as a random effect, and least squares means \pm standard error of the mean are reported.

The temperature-humidity index during the dry period was similar between pens and averaged $77.9 \pm$ 4.1 for CL pens and $77.6 \pm 4.1$ for HT pens, which indicated that both HT and CL cows were exposed to similar and significant environmental heat stress. Similar to previous studies (do Amaral et al., 2009, 2011; Tao et al., 2011), the cooling system effectively alleviated the heat strain in CL cows as indicated by decreased rectal temperature $(39.0 \pm 0.04$ vs. $39.4 \pm$ $0.04^{\circ} \mathrm{C}$, respectively; $P<0.001$ ) and respiration rate $(47.3 \pm 2.2$ vs. $71.2 \pm 2.2$ breaths per minute; respectively; $P<0.001)$ compared with HT cows. Thus, the effectiveness of the treatments was achieved and the experimental model was appropriate to compare the expression of autophagic proteins in $\mathrm{MG}$ tissue from these CL and HT cows at different time points during the early dry period.

In the present study, we found that during the early dry period both autophagosome-bound LC3-II and its cytosolic precursor LC3-I displayed a dynamic protein expression pattern in MG tissue from CL cows, which was blunted by heat stress. We detected a significant effect of treatment and a tendency for a treatment $x$ time interaction on LC3-I expression $(P=0.02$ and $P$ $=0.13$, respectively) and a tendency for a treatment $\times$ time interaction on LC3-II expression $(P=0.07)$. Specifically, protein expression of LC3-I and LC3-II in CL cows increased almost 2 -fold from d 3 before dry-off to d 7 after dry-off $(P=0.01$ and $P=0.02$, respectively) and decreased subsequently from $\mathrm{d} 7$ to 22 after dry-off $(P=0.01$ and $P=0.002$, respectively; Figure 1). In contrast, MG tissue from HT cows showed no significant differences in the expression of these proteins between d 3 before dry-off and d 22 after dry- off. Importantly, relative to HT cows, MG tissue from CL cows displayed higher expression of LC3-I $(P=$ $0.02)$ and LC3-II $(P=0.07)$ on d 7 after dry-off and lower expression of LC3-II on d $14(P=0.03)$ and $\mathrm{d}$ $22(P=0.08)$ after dry-off (Figure 1$)$. To the best of our knowledge, this is the first study to describe the dynamic pattern of autophagic activity in MG tissue during the early dry period and its alteration by heat stress. Autophagy in MG tissue from CL cows temporarily increased after dry-off, as indicated by increased expression of the autophagy protein LC3-I and LC3-II on d 7 after dry-off and its subsequent decrease (Figure 1). Our data further suggest that MG autophagy is negatively affected by chronic thermal stress (Figure 1). Specifically, we show here that cows exposed to environmental heat stress during the early dry period (1) lack the temporary stimulation of autophagy following milk stasis, which may prevent regenerative involution, and (2) lack the subsequent attenuation of autophagy observed in CL cows.

Surprisingly, expression of the autophagy protein Atg7 remained constant during the early dry period and was not affected by treatment (Figure 1). Autophagy protein 7 is a ubiquitin-activating E1-like protein necessary for the formation and expansion of the autophagosome by activating autophagy protein Atg12 for its conjugation with Atg5 as well as LC3-I for its conjugation with the lipid phosphatidylethanolamine (Komatsu et al., 2005). Both of these conjugation systems are necessary for integration of LC3-II in the autophagosomal membrane. Consequently, Atg7 has been used as a marker for the upregulation of autophagy upstream of LC3. The present study is the first to measure expression of Atg7 in MG tissue after dry-off. The lack of response to dry-off in Atg7 expression in CL cows is in contrast to the dynamic response of LC3 and suggests that Atg7 may not be limiting for the process of autophagosome formation in mammary tissue and, further, is unaffected by heat stress. However, it is possible that other proteins upstream of Atg7 and LC3 regulate autophagy induction upon dry-off and that those are sensitive to heat stress. For example, beclin-1 is a protein that acts upstream of Atg7 and LC3 and associates with a multimeric complex of autophagy regulatory proteins (Atg14, Vps34/class 3 PI3kinase, and Vps15) important for induction and formation of a pre-autophagosome structure (Kihara et al., 2001a,b). A significant increase of beclin-1 expression from late lactation to drying off was reported for MG tissue explants from Holstein dairy cows (Zarzynska et al., 2007) and supports a role for autophagy in a remodeling process that may be initiated in late lactation when milk production declines. However, the precise time of 

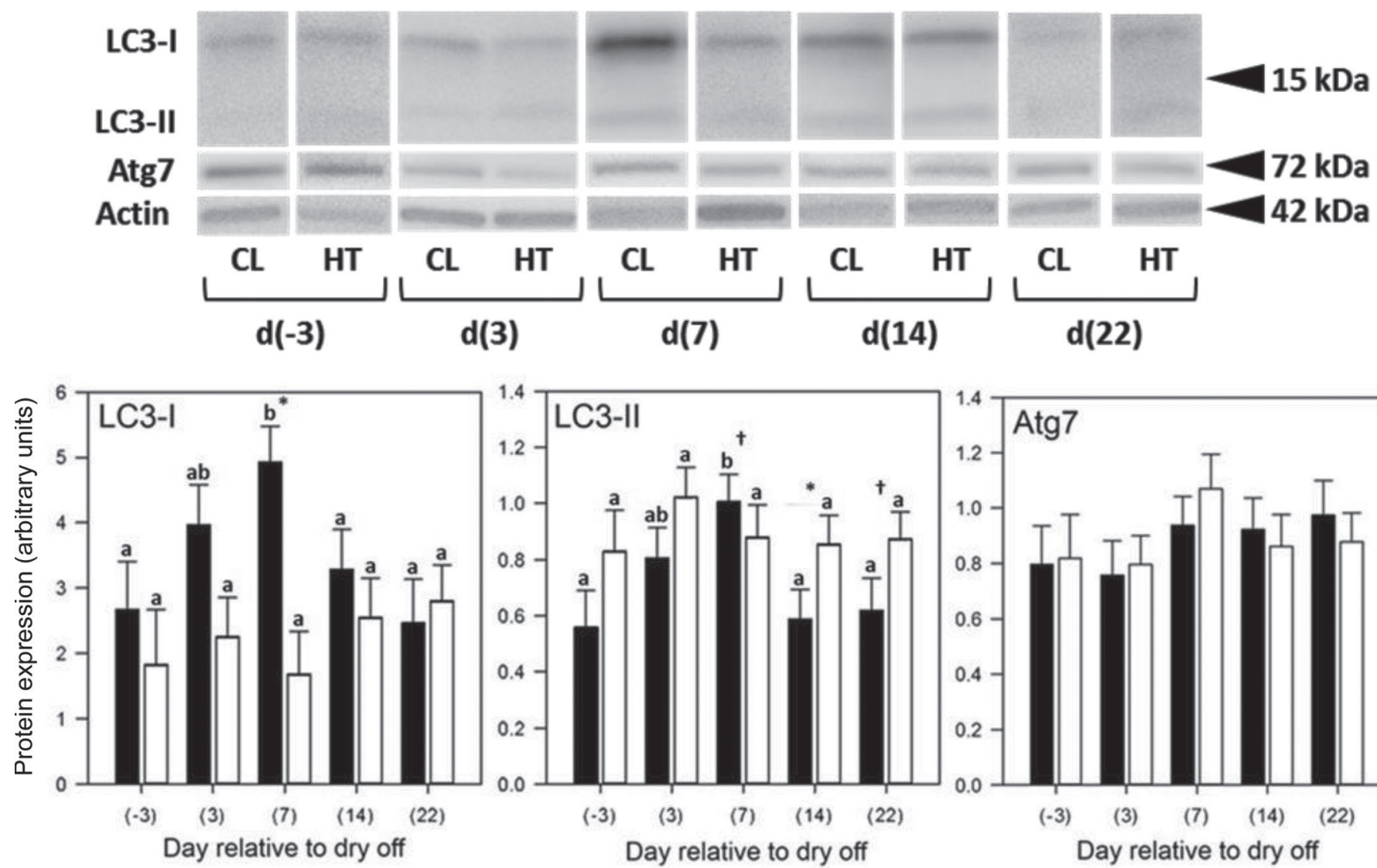

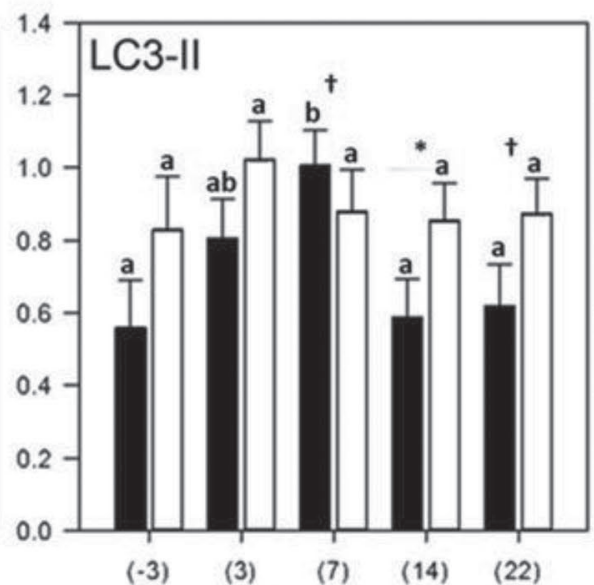

Day relative to dry off

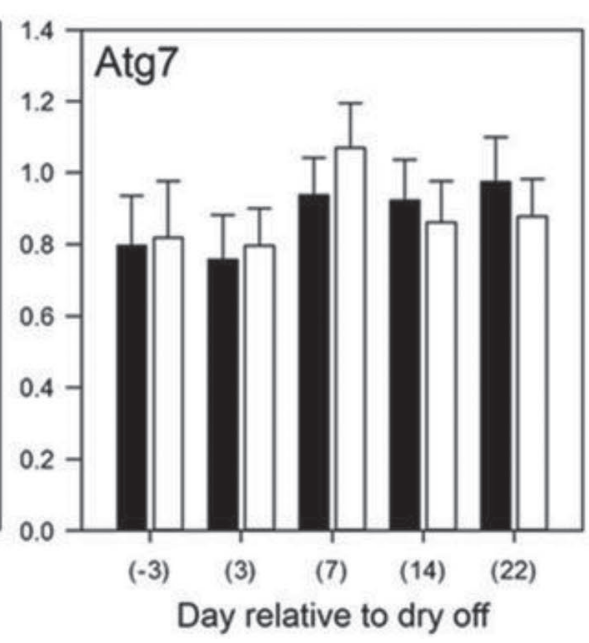

Figure 1. The protein expression of microtubule-associated protein light chain 3 (cytosolic LC3-I and autophagosome-bound LC3-II) and autophagy-related protein $7(\operatorname{Atg} 7)$ in mammary gland of heat stressed [HT; white bars; $\mathrm{n}=4, \mathrm{~d}(-3) ; \mathrm{n}=8(\mathrm{Atg} 7)$ or 7 (LC3), $\mathrm{d}(3)$; $\mathrm{n}=6$, $\mathrm{d}(7) ; \mathrm{n}=7, \mathrm{~d}(14) ; \mathrm{n}=8, \mathrm{~d}(22)]$ and cooled cows [CL; black bars; $\mathrm{n}=5, \mathrm{~d}(-3) ; \mathrm{n}=6$ (Atg7) or 7 (LC3), $\mathrm{d}(3) ; \mathrm{n}=8($ Atg7) or 7 (LC3), $\mathrm{d}(7)$; $\mathrm{n}=7, \mathrm{~d}(14) ; \mathrm{n}=6$ (Atg7) or 7 (LC3), $\mathrm{d}(22)$ ] during the early dry period. $\mathrm{d}(-3)=3 \mathrm{~d}$ before dry-off; $\mathrm{d}(3), \mathrm{d}(7), \mathrm{d}(14)$, and $\mathrm{d}(22)=3,7,14$, and $22 \mathrm{~d}$ after dry-off, respectively. Note that different sample sizes at the different time points are due to lack of sufficient biopsy specimens from some of the animals at some of the time points. The top panel displays representative immunoblots of LC3-I, LC3-II, Atg7, and $\beta$-actin for both treatments at each time point. Protein expression of LC3-I had a treatment effect $(P=0.02)$, and tendencies existed for treatment $\times$ time interactions for protein expression of LC3-I $(P=0.13)$ and LC3-II $(P=0.07)$. However, no differences in treatment or treatment $\times$ time interaction were observed for Atg7 expression. Protein expressions of LC3-I and LC3-II were elevated in cooled cows $7 \mathrm{~d}$ after dry-off $(P=0.01$ and $P=0.02$, respectively) but were unaffected by time in heat stressed cows. Compared with those from heat stressed cows, mammary glands from cooled cows displayed higher expression of LC3-I $(P=0.02)$ and LC3-II $(P=0.07) 7 \mathrm{~d}$ after dry-off and lower expression of LC3-II $14 \mathrm{~d}$ $(P=0.03)$ and $22 \mathrm{~d}(P=0.08)$ after dry-off. Data are shown as least squares means \pm standard error of the mean. $*(P<0.05)$ and $\dagger(P<$ $0.1)$ indicate difference between treatment groups at the same time point. Different letters $(\mathrm{a}, \mathrm{b})$ indicate differences between time points within the same treatment group $(P<0.05)$.

biopsy collection relative to dry-off was not indicated, and a time course of beclin-1 expression through the early dry period was not measured. It remains to be determined whether and to what extent autophagy is induced before or immediately after dry-off.

Our results support the concept that autophagic activity in MG tissue is temporarily stimulated after dry-off, and that heat stress perturbs this pattern by preventing this upregulation. Thus, the temporary increase in autophagy facilitates both the removal of senescent cells and the protection of progenitor and other well-functioning mammary cells during the early dry period, and its subsequent attenuation is necessary for
MG cell proliferation during the late dry period. Heat stress, in contrast, blunts this temporary upregulation in autophagy, which may lead to retention of cells that do not function optimally during the subsequent lactation. Furthermore, reduced autophagic housekeeping in MG progenitor cells during involution could impair the following proliferative capacity of these cells and, thus, subsequent milk production, as described previously in HT dry cows (Tao et al., 2011). Although we did not assess proliferation rate, we propose that the lack of autophagy attenuation after mammary involution that follows the blunted autophagy peak during involution in HT cows will hinder cell proliferation during the late 
dry period compared with CL, a proposition that is currently under investigation.

In addition to a direct effect of chronic environmental heat stress on MG autophagy, the blunted autophagic response to milk stasis observed in our study could have affected the rate of MG apoptosis. Crosstalk between autophagy and apoptosis has previously been suggested, based on numerous genes that are shared between the 2 pathways (Eisenberg-Lerner et al., 2009). Based on our present data, we cannot answer whether this crosstalk takes place during MG involution, and future studies are needed to assess the effect of environmental heat stress on the interplay between autophagy and apoptosis in the early dry period.

Collectively, our data provide a possible mechanistic explanation for the impairment of MG capacity in HT dairy cows. Heat stress-related perturbations of autophagic activity may compromise the regenerative $\mathrm{MG}$ involution that is necessary for optimal cell proliferation. Based on the presented data it remains unclear at which point in the autophagy pathway from induction to degradation the negative effect of heat stress occurs. To address this question, future studies will have to assess the effect of heat stress on various checkpoints along the autophagy pathway. In addition, the interconnectivity between autophagy and apoptosis in the process of MG remodeling needs to be further explored. This knowledge will facilitate the development of novel strategies to alleviate the negative effect of environmental heat stress on milk production, targeting the role of autophagy in MG remodeling during the dry period.

\section{ACKNOWLEDGMENTS}

The authors thank the staff of the dairy unit at University of Florida (Hague) for animal care. This study was supported by the USDA-Agriculture and Food Research Institute (USDA/NIFA AFRI) Foundational Program Award \#2015-67015-23409 to G. E. Dahl, S. Tao, and S. E. Wohlgemuth.

\section{REFERENCES}

Abeliovich, H., W. A. Dunn Jr., J. Kim, and D. J. Klionsky. 2000. Dissection of autophagosome biogenesis into distinct nucleation and expansion steps. J. Cell Biol. 151:1025-1034. http://dx.doi. org/10.1083/jcb.151.5.1025.

Capuco, A. V., and R. M. Akers. 1999. Mammary involution in dairy animals. J. Mammary Gland Biol. Neoplasia 4:137-144.

Capuco, A. V., R. M. Akers, and J. J. Smith. 1997. Mammary growth in Holstein cows during the dry period: Quantification of nucleic acids and histology. J. Dairy Sci. 80:477-487.

Capuco, A. V., and S. E. Ellis. 2013. Comparative aspects of mammary gland development and homeostasis. Annu. Rev. Anim. Biosci. 1:179-202.
Codogno, P., and A. J. Meijer. 2005. Autophagy and signaling: their role in cell survival and cell death. Cell Death Differ. 12(Suppl. 2):1509-1518. http://dx.doi.org/10.1038/sj.cdd.4401751.

Collier, R. J., G. E. Dahl, and M. J. VanBaale. 2006. Major advances associated with environmental effects on dairy cattle. J. Dairy Sci. 89:1244-1253.

Collier, R. J., S. G. Doelger, H. H. Head, W. W. Thatcher, and C. J. Wilcox. 1982. Effects of heat-stress during pregnancy on maternal hormone concentrations, calf birth-weight and postpartum milkyield of Holstein cows. J. Anim. Sci. 54:309-319.

do Amaral, B. C., E. E. Connor, S. Tao, J. Hayen, J. Bubolz, and G. E. Dahl. 2009. Heat-stress abatement during the dry period: Does cooling improve transition into lactation? J. Dairy Sci. 92:59885999. http://dx.doi.org/10.3168/jds.2009-2343.

do Amaral, B. C., E. E. Connor, S. Tao, M. J. Hayen, J. W. Bubolz, and G. E. Dahl. 2011. Heat stress abatement during the dry period influences metabolic gene expression and improves immune status in the transition period of dairy cows. J. Dairy Sci. 94:86-96. http://dx.doi.org/10.3168/jds.2009-3004.

Eisenberg-Lerner, A., S. Bialik, H. U. Simon, and A. Kimchi. 2009. Life and death partners: Apoptosis, autophagy and the crosstalk between them. Cell Death Differ. 16:966-975. http://dx.doi. org/10.1038/cdd.2009.33.

Gajewska, M., K. Zielniok, and T. Motyl. 2013. Autophagy in development and remodelling of mammary gland. Chapter 20 in Autophagy - A Double-Edged Sword-Cell Survival or Death? Y. Bailly, ed. InTech, Rijeka, Croatia. http://dx.doi.org/10.5772/54558.

Hsu, S. F., C. M. Chao, W. T. Huang, M. T. Lin, and B. C. Cheng. 2013. Attenuating heat-induced cellular autophagy, apoptosis and damage in H9c2 cardiomyocytes by pre-inducing HSP70 with heat shock preconditioning. Int. J. Hyperthermia 29:239-247. http:// dx.doi.org/10.3109/02656736.2013.777853.

IPCC (Intergovernmental Panel on Climate Change). 2013. Summary for policymakers. Pages 1-29 in Climate Change 2013: The Physical Science Basis. Contribution of Working Group I to the Fifth Assessment Report of the Intergovernmental Panel on Climate Change. T. F. Stocker, D. Qin, G.-K. Plattner, M. Tignor, S. K. Allen, J. Boschung, A. Nauels, Y. Xia, V. Bex, and P. M. Midgley, ed. Cambridge Univ. Press, Cambridge, United Kingdom.

Kihara, A., Y. Kabeya, Y. Ohsumi, and T. Yoshimori. 2001a. Beclinphosphatidylinositol 3-kinase complex functions at the trans-Golgi network. EMBO Rep. 2:330-335. http://dx.doi.org/10.1093/ embo-reports/kve061.

Kihara, A., T. Noda, N. Ishihara, and Y. Ohsumi. 2001b. Two distinct Vps34 phosphatidylinositol 3-kinase complexes function in autophagy and carboxypeptidase Y sorting in Saccharomyces cerevisiae. J. Cell Biol. 152:519-530. http://dx.doi.org/10.1083/ jcb.152.3.519

Komatsu, M., S. Waguri, T. Ueno, J. Iwata, S. Murata, I. Tanida, J. Ezaki, N. Mizushima, Y. Ohsumi, Y. Uchiyama, E. Kominami, K. Tanaka, and T. Chiba. 2005. Impairment of starvation-induced and constitutive autophagy in Atg7-deficient mice. J. Cell Biol. 169:425-434. http://dx.doi.org/10.1083/jcb.200412022.

Nivon, M., E. Richet, P. Codogno, A. P. Arrigo, and C. Kretz-Remy. 2009. Autophagy activation by NFkappaB is essential for cell survival after heat shock. Autophagy 5:766-783.

Parzych, K. R., and D. J. Klionsky. 2014. An overview of autophagy: morphology, mechanism, and regulation. Antioxid. Redox Signal. 20:460-473. http://dx.doi.org/10.1089/ars.2013.5371.

Qu, X., J. Yu, G. Bhagat, N. Furuya, H. Hibshoosh, A. Troxel, J. Rosen, E. L. Eskelinen, N. Mizushima, Y. Ohsumi, G. Cattoretti, and B. Levine. 2003. Promotion of tumorigenesis by heterozygous disruption of the beclin 1 autophagy gene. J. Clin. Invest. 112:1809-1820. http://dx.doi.org/10.1172/JCI20039.

Sobolewska, A., M. Gajewska, J. Zarzynska, B. Gajkowska, and T. Motyl. 2009. IGF-I, EGF, and sex steroids regulate autophagy in bovine mammary epithelial cells via the mTOR pathway. Eur. J. Cell Biol. 88:117-130. http://dx.doi.org/10.1016/j.ejcb.2008.09.004.

Tanida, I., T. Ueno, and E. Kominami. 2004. LC3 conjugation system in mammalian autophagy. Int. J. Biochem. Cell Biol. 36:25032518. http://dx.doi.org/10.1016/j.biocel.2004.05.009. 
Tao, S., J. W. Bubolz, B. C. do Amaral, I. M. Thompson, M. J. Hayen, S. E. Johnson, and G. E. Dahl. 2011. Effect of heat stress during the dry period on mammary gland development. J. Dairy Sci. 94:5976-5986. http://dx.doi.org/10.3168/jds.2011-4329.

Teplova, I., F. Lozy, S. Price, S. Singh, N. Barnard, R. D. Cardiff, R. B. Birge, and V. Karantza. 2013. ATG proteins mediate efferocytosis and suppress inflammation in mammary involution. Autophagy 9:459-475. http://dx.doi.org/10.4161/auto.23164.

Wall, E. H., T. L. Auchtung, G. E. Dahl, S. E. Ellis, and T. B. McFadden. 2005. Exposure to short day photoperiod during the dry period enhances mammary growth in dairy cows. J. Dairy Sci. 88:19942003. http://dx.doi.org/10.3168/jds.S0022-0302(05)72875-7.

Wang, R. C., and B. Levine. 2010. Autophagy in cellular growth control. FEBS Lett. 584:1417-1426. http://dx.doi.org/10.1016/j. febslet.2010.01.009.

West, J. W. 2003. Effects of heat-stress on production in dairy cattle. J. Dairy Sci. 86:2131-2144.
Wohlgemuth, S. E., A. Y. Seo, E. Marzetti, H. A. Lees, and C. Leeuwenburgh. 2010. Skeletal muscle autophagy and apoptosis during aging: Effects of calorie restriction and life-long exercise. Exp. Gerontol. 45:138-148. http://dx.doi.org/10.1016/j.exger.2009.11.002.

Wolfenson, D., I. Flamenbaum, and A. Berman. 1988. Dry period heat stress relief effects on prepartum progesterone, calf birth weight, and milk production. J. Dairy Sci. 71:809-818.

Zarzynska, J., B. Gajkowska, U. Wojewodzka, E. Dymnicki, and T. Motyl. 2007. Apoptosis and autophagy in involuting bovine mammary gland is accompanied by up-regulation of TGF-beta(1) and suppression of somatotropic pathway. Pol. J. Vet. Sci. 10:1-9.

Zarzynska, J., and T. Motyl. 2008. Apoptosis and autophagy in involuting bovine mammary gland. J. Physiol. Pharmacol. 59:275-288.

Zhao, Y., S. Gong, E. Shunmei, and J. Zou. 2009. Induction of macroautophagy by heat. Mol. Biol. Rep. 36:2323-2327. http://dx.doi org/10.1007/s11033-009-9451-4. 